\title{
Perancangan Sistem Pemesanan Rumah Sakit di Kota Malang Menggunakan Ionic Framework berbasis Mobile Phone
}

\author{
M. Rofiq ${ }^{1}$, Suci Imani Putri ${ }^{2}$ \\ STMIK ASIA Malang \\ e-mail: ${ }^{1}$ Rofiq@asia.ac.id, ${ }^{2}$ s.imaniputri@gmail.com
}

\begin{abstract}
ABSTRAK. Aplikasi pemesanan fasilitas rumah sakit merupakan sebuah aplikasi yang diharapkan dapat memudahkan para pasien untuk proses pemesanan fasilitas yang disediakan oleh pihak rumah sakit. Pembuatan aplikasi ini didasarkan karena banyaknya para pengguna smartphone dan tablet. Aplikasi dibuat agar pasien dapat mengakses informasi atau melakukan pemesanan fasilitas dimanapun dan kapanpun.Dalam aplikasi terdapat beberapa fitur yang dapat memudahkan pengguna dalam mendapatkan kemudahan tanpa harus mendatangi pihak rumah sakit dalam proses pemesanan. Proses perancangan web administrator dan Aplikasi menggunakan Mekanisme MVC yang merupakan system pengembangan aplikasi yang terpisah, Komponen utama berbasis itu yang membangun aplikasi seperti manipulasi data (Model), user interface (View), dan bagian kontrol (Controller) dalam aplikasi web. Implementasi MVC (Model View Controller) dengan CodeIgniter Framework, membuat system pada aplikasi menjadi lebih mudah untuk dikembangkan oleh pengembang berikutnya. Pembuatan Aplikasi pada smartphone dibuat dengan menggunakan Ionic Framework dengan dasar PHP, JavaScript Framework AngularJS, dan Node.js. Setelah melalui proses pengujian yang telah dilakukan, aplikasi yang dibuat menampilkan informasi berupa jadwal poliklinik serta nama dokter, melakukan pemesanan pada poliklinik yang disediakan pihak rumah sakit, pemesanan kamar untuk rawat inap, serta mengetahui jumlah tagihan yang harus dibayarkan, hingga fitur komunikasi dengan pihak rumah sakit untuk mendapatkan informasi yang diinginkan dan hasil survey kepada pengguna aplikasi menunjukkan tingkat kepuasan sebesar 80,13\%.
\end{abstract}

Kata kunci:Aplikasi pemesanan rumah sakit, Smartphone, Ionic Framework, CodeIgniter Framework, MVC(Model, View, Controller)

ABSTRACT. Hospital facility booking application is an application that is expected to facilitate the patients for the process of booking facilities provided by the hospital. Making this application is based because of the many users of smartphones and tablets. Applications are made so that patients can access information or make reservations facilities wherever and whenever. In the application there are several features that can facilitate the user in getting the ease without having to go to the hospital in the order process. The process of designing web administrators and Applications using MVC Mechanism is a separate application development system, the main component that builds such applications as data manipulation (Model), user interface (View), and controls (Controller) in web applications. Implementation MVC (Model View Controller) with CodeIgniter Framework, making the system on the application becomes easier to be developed by the next developer. Application creation on smartphones is created using Ionic Framework with basic PHP, JavaScript Framework AngularJS, and Node.js. After going through the testing process that has been done, the application is made to display information in the form of polyclinic schedule as well as the name of the doctor, make reservations at the clinic provided by the hospital, bookings for hospitalization, and know the amount of bills to be paid, to communication features with the home sick to get the desired information and survey results to the user application shows the satisfaction level of $80.13 \%$.

Keywords: Hospital booking app, Smartphone, Ionic Framework, CodeIgniter Framework, MVC (Model, View, Controller)

\section{PENDAHULUAN}

Rumah sakit adalah sebuah institusi perawatan kesehatan profesional yang pelayanannya disediakan oleh dokter,perawat, dan tenaga ahli kesehatan lainnya. Perbandingan antara jumlah tempat tidur rumah sakit dengan jumlah penduduk Indonesia masih sangat rendah. Untuk 10 ribu penduduk cuma tersedia 6 ranjang rumah sakit. Selama abad pertengahan, rumah sakit juga melayani banyak fungsi di luar rumah sakit yang kita kenal pada zaman sekarang, misalnya sebagai penampungan orang miskin atau persinggahan musafir. Istilah hospital (rumah sakit) berasal dari kata Latin,hospes (tuan rumah), yang juga menjadi akar kata hotel dan hospitality (keramahan). Beberapa pasien bisa hanya datang untuk diagnosis atau terapi ringan untuk kemudian meminta perawatan jalan, atau bisa pula meminta rawat inap dalam hitungan hari, minggu, atau bulan. Rumah sakit dibedakan dari institusi kesehatan lain dari kemampuannya memberikan diagnosa dan perawatan medis secara menyeluruh kepada pasien [1].

Fungsi lain rumah sakit tidak hanya menyembuhkan dan merawat melainkan memiliki beberapa fasilitas yang wajib dimiliki sebagai penunjang keberlangsungan dalam perawatan pasien. Fasilitas dalam sebuah rumah sakit diantaranya adalah pelayanan gawat darurat, pelayanan rawat jalan, pelayanan rawat inap, pelayanan bedah, pelayanan persalinan dan perinatologi, pelayanan intensif, pelayanan radiologi, pelayanan laboratorium patologi klinik, pelayanan rehabilitasi medik, pelayanan farmasi, dan fasilitas penunjang lainnya. Dengan berbagai banyaknya fasilitas sering kali pasien tidak mengetahui fasilitas apa saja yang disediakan, karena semua proses transaksi dilakukan secara manual dan langsung ke rumah sakit. Selain itu, cara lain dapat dilakukan dengan melalui telepon.Dengan tambahan fitur-fitur baru pada perangkat mobile phone atau smartphone produk mereka. Contohnya, dengan perangkat smartphone saja kita dapat mengakses berbagai 
macam informasi melalui internet. Dengan adanya perangkat smartphone serta dengan kecanggihan yang ditawarkan dan kemudahan yang bisa kita dapatkan, banyak hal yang dapat di akses dimanapun kita berada [2].

Demi menunjang fasilitas untuk kemudahaan seorang pasien perlu sebuahpengembangan dimana pasien dapat dengan mudah mengakses fasilitas apapun yang disediakan rumah sakit melalui telepon genggam. Selain fasilitas, pengambilan hasil laboratorium serta konsultasi dengan dokter spesialis maupun penanganan juga diharapkan dapat dirangkum menjadi suatu sistem.Dari permasalahan diatas maka perlu dirancang sebuah aplikasi pemesanan fasilitas rumah sakit yang dapat diakses melalui telepon genggam pasien maupun calon pasien. Perancangan sebuah aplikasi berbasis mobile ditujukan bagi pengguna android dan ios, karena ini dipilih model ionic framework. Dimana ionic framework merupakan sebuah mobile hybrid yang mampu digunakan di platform smartphone, seperti Android, iOS. Dibandingkan dengan framework jQuery, Ionic jauh lebih cepat. Ionic menggunakan AngularJS,Node.js,SASS sebagai mesinnya. Seperti mobile framework kebanyakan, Ionic juga memiliki komponen/elemen CSS standar digunakan untuk smartphone, seperti button, list, card, form, range, tabs, grid dan lainnya [3]. Cukup lengkap, walaupun masih terus dikembangkan. Ionic juga open source, jadi dapat digunakan untuk kebutuhan apapun. Selain itu Ionic memanfaatkan AngularJS untuk implementasi logicnya. Jika menggunakan jQuery terkenal lambat di mobile sedangkan Angular menawarkan performa dan respon cepat serasa aplikasi native.

Hal khusus yang mendorong rumah sakit untuk memiliki aplikasi pemesanan adalah sebuah bentuk strategi pengembangan di bidang teknologi informasi dalam memenuhi permintaan kebutuhan akan sebuah informasi dan pelayanan dalam sebuah rumah sakit serta keuntungan kompetitif dalam segi kemudahan pasien.Berdasarkan paparan ini maka rencana pembentukan serta penerapan teknologi informasi dalam sebuah sistem informasi di rumah sakit berupa aplikasi pemesanan fasilitas perlu dibuat agar setiap rumah sakit mampu meningkatkan pelayanan pada pasien dan calon pasien dari segi kemudahaan dalam menggunakan fasilitas yang telah disediakan oleh rumah sakit. Harapannya rumah sakit di kota malang khususnya rumah sakit- rumah sakit besar dapat lebih diandalkan di bidang teknologi informasi. Dengan meningkatnya pelayanan rumah sakit maka akan meningkatkan kepuasan dan kepercayaan masyarakat dan bermaksud sebagai upaya dalam peningkatan pelayanan terhadap masayarakat agar lebih mudah dan cepat dalam menerima pelayanan.

\section{LANDASAN TEORI}

\subsection{Ionic Framework}

Framework Ionic adalah sekumpulan teknologi yang dikembangkan untuk membangun aplikasi mobile hybrid yang powerful, cepat, mudah dan juga memiliki tampilan yang menarik. Ionic menggunakan AngularJS sebagai framework berbasis web dan menggunakan Cordova untuk membangun aplikasi mobile. Ionic Framework merupakan framework HTML5 yang masih baru, dirilis 2 tahun lalu. Framework ini membantu Anda dalam mengembangkan aplikasi mobile dengan teknologi web seperti HTML, CSS dan Javascript.

Ionic platform menggunakan lisensi opensource, boleh digunakan oleh siapapun untuk membuat aplikasi free ataupun komersial dengan Ionic.Ionic memanfaatkan AngularJS untuk implementasi logicnya. Jika menggunakan jQuery terkenal lambat di mobile sedangkan Angular menawarkan performa dan respon cepat serasa aplikasi native.

\subsection{PHP dan MySQL}

PHP (Hypertext Preprocessor) pemrograman interpreter yaitu proses penerjemahan baris kode sumber menjadi kode mesin yang dimengerti komputer secara langsung pada saat baris kode dijalankan,disebut juga sebagai pemrograman Server Slide Programing, hal ini dikarenakan seluruh prosesnya dijalankan oleh server. PHP adalah program yang dikembangkan secara bersama oleh para programer dari seluruh dunia yang menekuni dunia open source, PHP dikembangkan khususnya untuk mengakses dan memanipulasi datayang ada di data base server open source seperti MySQL karena memiliki tingkat kompatibilitas yang sangat baik.

PHP mengenal pengolahan data menggunakan file teks,tetapi menyimpan data dalam file biasa memiliki banyak keterbatasan. File teks tidak memiliki kemampuan mengolah data seperti menghitung total nilai, ratarata,dan sebagainya, untuk itulah diperlukan data base seperti $M y S Q L$, dengan data base program akan lebih mudah mengendalikan akses terhadap data. MySQL atau dibaca "MySekuel" adalah suatu relational data base management system yaitu aplikasi sistem yang menjalankan fungsi pengolahan data. MySQL merupakan salah satu data base terbesar yang digunakan dalam pengolahan data di dunia. Hal ini terbukti digunakannya $M y S Q L$ oleh beberapa perusahaan dan institusi besar duniaseperti NASA,Yahoo!Finance, Aizawa (JapaneseSecurity), dll.

\subsection{Java Script}

Java adalah bahasa pemrograman serbaguna, dapat digunakan untuk membuat suatu program sebagaimana dapat dibuat dengan bahasa pemrograman lain seperti pascal atau $\mathrm{C}++$. Java mendukung sumber daya internet WorldWide Web atau yang biasa disebut denganWeb, mendukung aplikasi klient/server,baik dalam jaringan lokal(LAN) maupun jaringan (WAN).

Dalam sejumlah literatur disebutkan bahwa Java merupakan hasil perpaduan sifat dari sejumlah bahasa pemrograman, yaitu C, C++, Object-C, dll. Selain itu Java dilengkapi dengan unsur keamanan,yang tak kalah penting adalah bahwa Java menambahkan paradigma pemrograman sederhana, jika mengenal bahasa 
pemrograman $\mathrm{C}$ atau $\mathrm{C}++$, yang mengandalkan pointer dan merasakan kerumitannya, Java justru meninggalkannya, sehingga akan diperoleh kemudahan saat menggunakannya. Java Script adalah bahasa pemrograman yang dapat memegang kontrol aplikasi, berorientasi objek murni dan digunakan secara prosedural. Java Script merupakan bahasa yang case sensitive sepertihalnya bahasa pemrograman Java yaitu membedakan penulisan dengan huruf kecil dan huruf besar memberi arti yang berbeda. Java menggunakan kelas untuk membentuk suatu objek. Sejumlah kelas sudah tersediadan dapat digunakan dengan mudah, bahkan dapat dikembangkan jauh melebihi konsep pewarisan, yang dimaksud pewarisan adalah sifat yang ada pada bahasa pemrograman berorientasi objek yang memungkinkan sifat-sifat suatu objek diturunkan dengan mudah ke objek lain.

\section{ANALISA DAN PERANCANGAN SISTEM}

\subsection{Analisa Masalah}

Proses awal administrasi seorang pasien sangat tidak efisien karena banyak membuang waktu,sehingga kurang memuaskan pasien, dengan adanya sebuah aplikasi pemesanan yang akan dirancang, maka pasien dengan mudah mengetahui apa saja fasilitas yang disediakan oleh rumah sakit, serta mendaftar melalui telepon genggam tanpa harus datang langsung, sehingga akan sangat membantu pasien dalam segi waktu. Berikut adalah kerangka permasalahan.

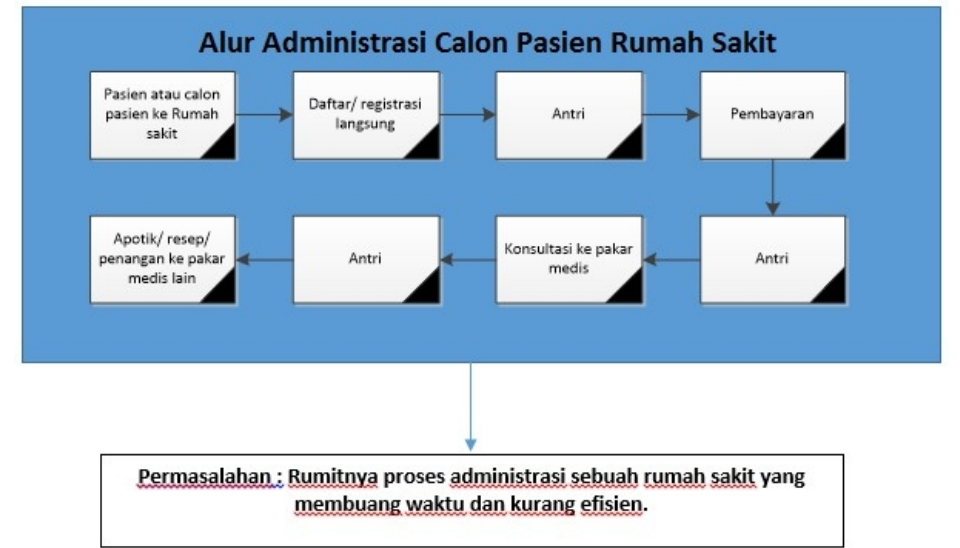

Gambar 1. Kerangka Permasalahan

\subsection{Perancangan Sistem}

Perancangan sistem Untuk menyelesaikan rumusan masalah dan merealisasikan tujuan penelitian menggunakan tahapan - tahapan dapat diuraikan sebagaiberikut:

\section{PenentuanBahandan Alat}

Bahan(komponen) dan alat yang diperlukan dalam pelaksanaan penelitian ini adalah sebagai berikut:
a. PersonalKomputer (PC)
b. Mobilephone
c. Software

\section{SpesifikasiSistem}

Sistem aplikasi pemesanan fasilitas rumah sakit yang akan dirancang diharapkan memiliki spesifikasi sebagai berikut:
a. Registrasi user
b. Login User
c. Map (lokasi rumah sakit, sertadenah rumah sakit)
d. Aplikasi chat(obrolan) dengan admin, pakar medis,customer service
e. Toolbar registrasi fasilitas untuk pemesanan
f. Pembayaran
g. Bantuan (help)
h. Gallery fasilitas yang disediakan
i. Daftar Antrian

\section{Perancangan Sistem}

Perancangan sistem meliputi penentuan fungsi sistem, melakukan perancangan data base, perancangan system user interface, pengaturan server dan data base, pembuatan model pengambilan data, pengambilan data dan integrasi user interface.

\section{Perancangan Software}

Untuk pengujian perangkat lunak, pengujian dilakukan dengan cara mensimulasikan hasil perancangan perangkat lunak, kemudian dilakukan pengujian bersama perangkat keras untuk mengetahui respon yang 
dihasilkan. Pengujian perangkat lunak bertujuan untuk mengetahui apakah perangkat lunak tersebut dapat mengolah data serta mengontrol sistem sesuai dengan perancangan yang telah dibuat.

5. Pengujian Alat pada Mobile Phone

Pengujian dilakukan untuk menganalisis alat yang dibuat telah memberikan hasil sesuai dengan yang direncanakan atau tidak. Pengujian dilakukan secara per blok terlebih dahulu dan kemudian secara keseluruhan sistem.

\section{Pengambilan Kesimpulan}

Setelah mendapatkan hasil analisis daripengujian alat, maka langkah berikutnya yang dilakukan adalah pengambilan kesimpulan dan pemberian saran. Penarikan kesimpulan dilakukan berdasarkan kesesuaian antara perancangan dan hasil pengujian

\subsection{Pembuatan Aplikasi}

Proses pembuatan aplikasi dibagi menjadi pembuatan web administrator dan pembuatan perancangan aplikasi pada telepon genggam, tahapan dalam perancangan dan pembuatan secara rinci sebagai berikut:

\section{a) Perancangan dan Pembuatan Basis Data}

Basis data yang digunakan menggambarkan entitas-entitas yang ada, atribut-atribut dari masing masing entitas tersebut serta hubungan antar entitas tersebut secara Conseptual (berdasarkan pada konsep-konsep) [4]. Proses perancangan dan pembuatan aplikasi akan ditunjukkan dalam Gambar 2.
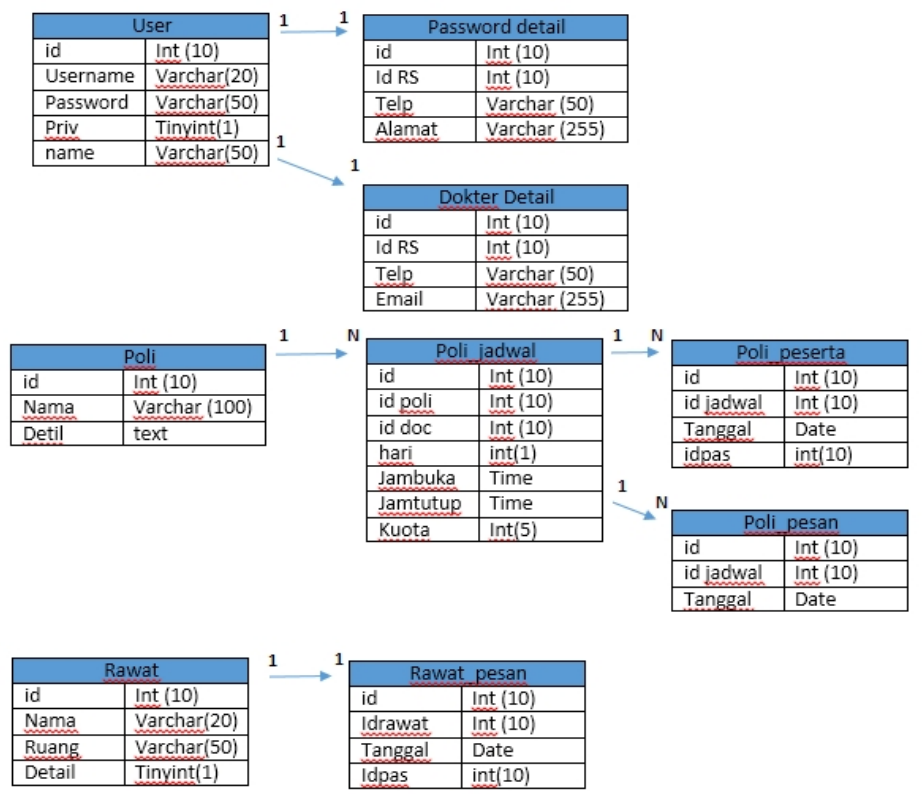

Gambar 2. Proses Perancangan Database

\section{b) Perancangan Admin Page}

Perancangan dan pembuatan untuk Admin Page menggunakan model view controller (MVC) dimana proses pengerjaan adalah merancang model dan view kemudian digabungkan dengan controller.

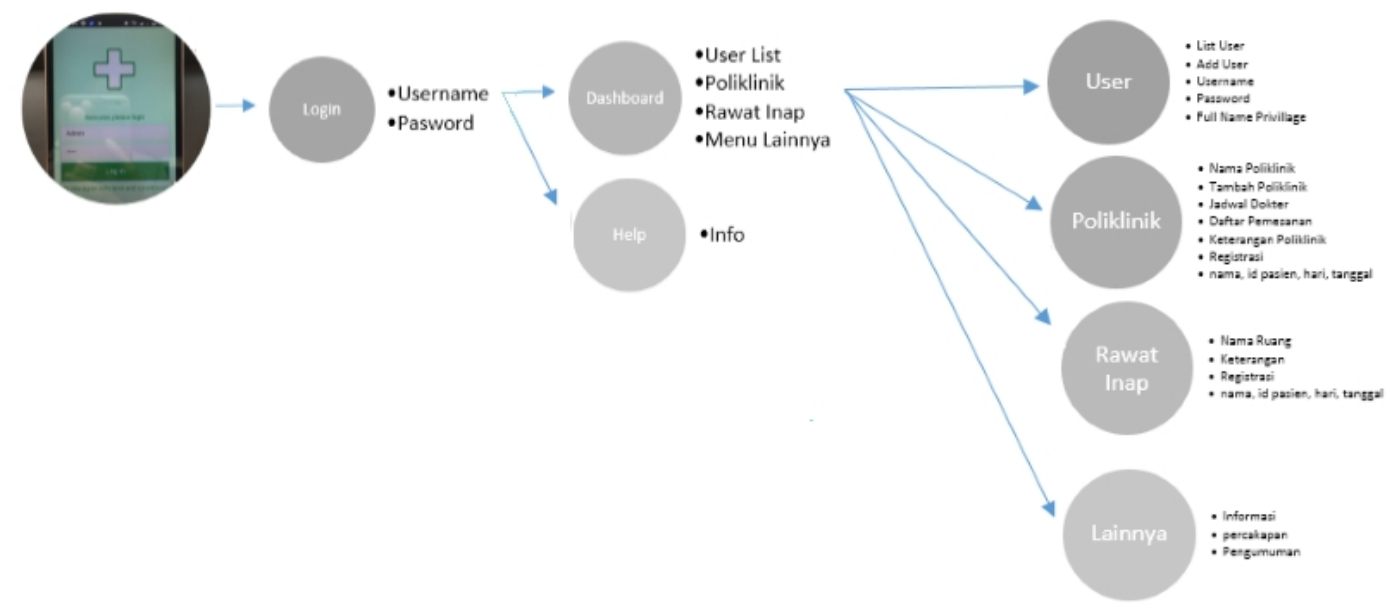

Gambar 3. Proses Perancangan MVC untuk Admin Page 
Pola MVC pada perancangan web administrator memiliki layer yang disebut dengan Model yang merepresentasikan data yang digunakan oleh aplikasi sebagaimana proses bisnis yang diasosiasikan terhadapnya. Dengan memilahnya sebagai bagian terpisah, seperti penampungan data, persistence, serta proses manipulasi, terpisah dari bagian lain aplikasi. Terdapat beberapa kelebihan dalam pendekatan ini. Pertama, membuat detail dari data dan operasinya dapat ditempatkan pada area yang ditentukan (Model) dibanding tersebar dalam keseluruhan lingkup aplikasi. Hal ini memberikan keuntungan dalam proses pemeliharaan aplikasi. Kedua, dengan pemisahan total antara data dengan implementasi interface, komponen model dapat digunakan kembali oleh aplikasi lain yang memiliki kegunaan yang hampir sama.

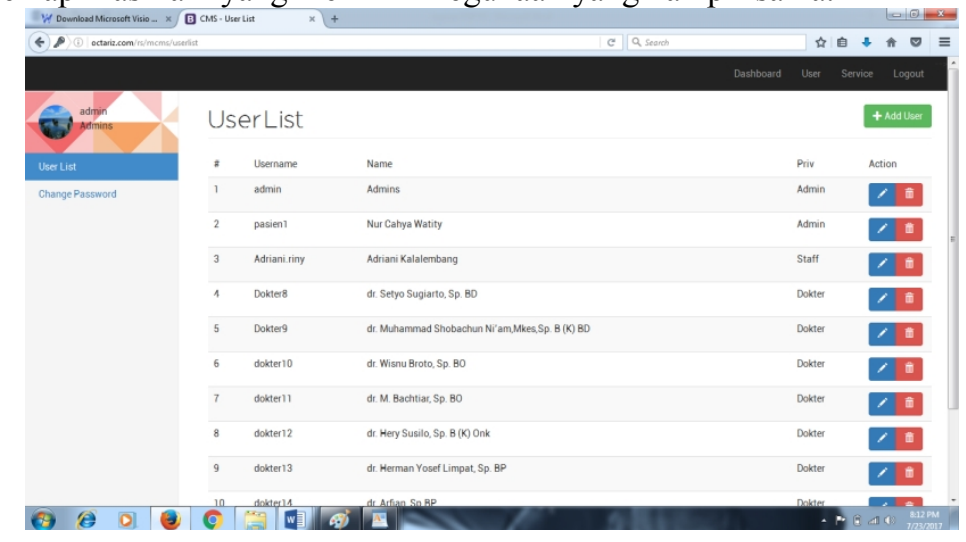

Gambar 4. Hasil Tampilan Untuk Admin Page

\section{c) Perancangan dan Pembuatan Aplikasi pada Mobile Phone}

Proses perancangan dan pembuatan aplikasi juga menggunakan model view controller, proses sama dengan perancangan content management system yang dibahas sebelumnya.Konsep "MVC atau Model-ViewController adalah sebuah metode untuk membuat sebuah aplikasi dengan memisahkan data (Model) dari tampilan (View) dan cara bagaimana memprosesnya (Controller). Dalam implementasinya kebanyakan framework dalam sebuah aplikasi adalah berbasis arsitektur MVC [5]. Model mewakili struktur data. Biasanya model berisi fungsi-fungsi yang membantu seseorang dalam pengelolaan basis data seperti memasukkan data ke basis data, pembaruan data dan lain-lain. View adalah bagian yang mengatur tampilan ke pengguna. Bisa di katakan berupa halaman website. Controller merupakan bagian yang menjembatani Model dan View. Controller berisi perintah-perintah yang berfungsi untuk memproses suatu data dan mengirimkannya ke halaman website. class ini biasanya mengextends dari class-class Activity, Fragment dan Adaptor. Berikut MVC Workflow pada umumnya :
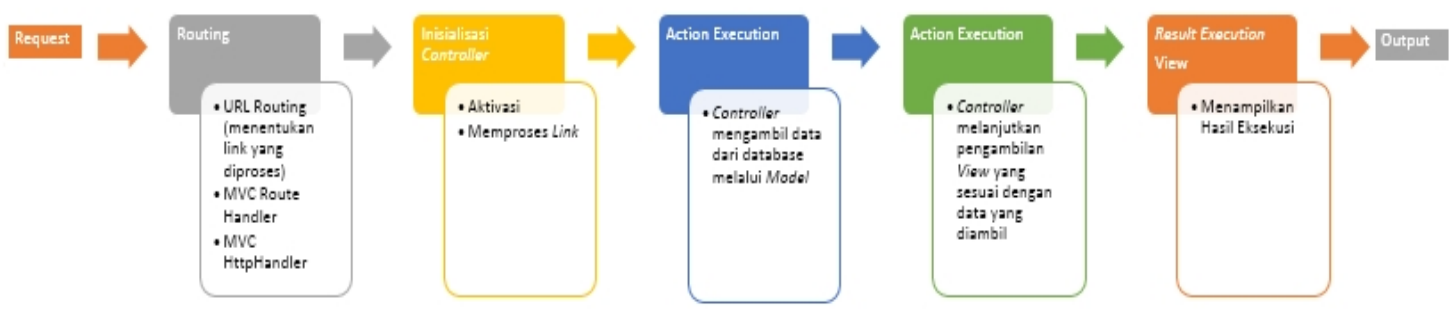

Gambar 5. Perancangan MVC pada Mobile Phone

MVC memiliki beberapa layer, dimana Layer ini menyediakan detail alur program dan transisi layer, dan juga bertanggungjawab akan penampungan events yang dibuat oleh user dari View dan melakukan update terhadap komponen Model menggunakan data yang dimasukkan oleh user. Kelebihan dalam penggunaan layer Controller secara terpisah: Pertama, dengan menggunakan komponen terpisah untuk menampung detail dari transisi layer, komponen view dapat didesain tanpa harus memperhatikan bagian lain secara berlebih [6]. Hal ini memudahkan team pengembang multiple interface bekerja secara terpisah dari yang lain secara simultan. Interaksi antar komponen View terabstraksi dalam Controller. Perancangan pada aplikasi sublime sebagai berikut: 


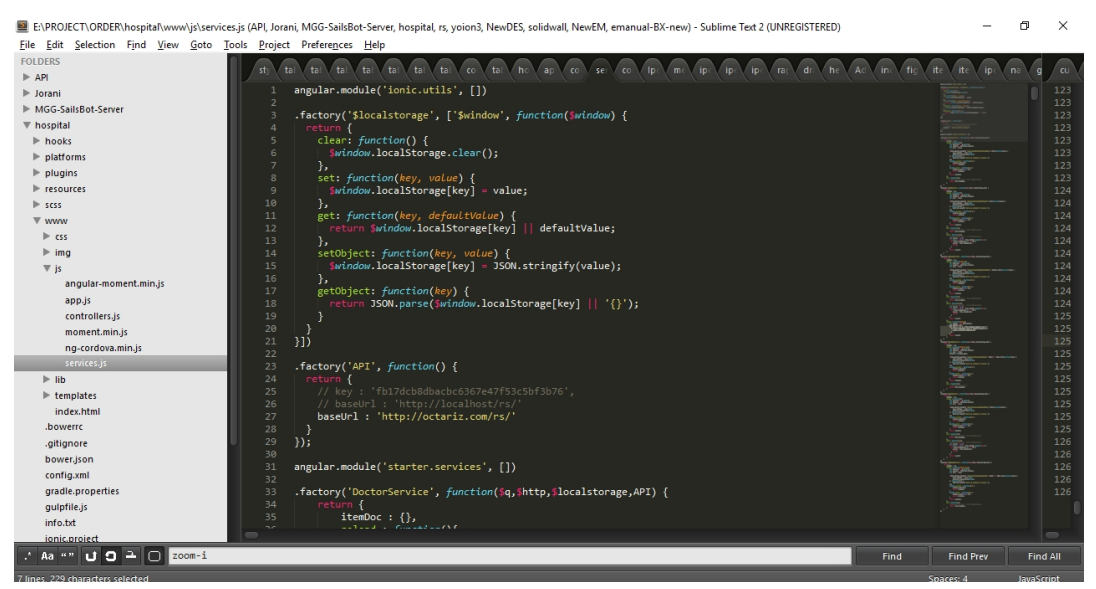

\section{$4 \quad$ Pengujian}

Gambar 6. Proses Pembuatan Program MVC

Pengujian ini dilakukan dengan cara membangun aplikasi pada berbagai pengguna mobile phone dan membagikan kuisioner terhadap fasilitas yang diberikan oleh aplikasi kepada pengguna. Untuk pengujian dijelaskan sebagai berikut.

\section{a) Pengujian pada Mobile Phone}

Tampilan pada mobile phone dan proses berjalannya aplikasi ditunjukkan berdasarkan diagram alir sebagai berikut:

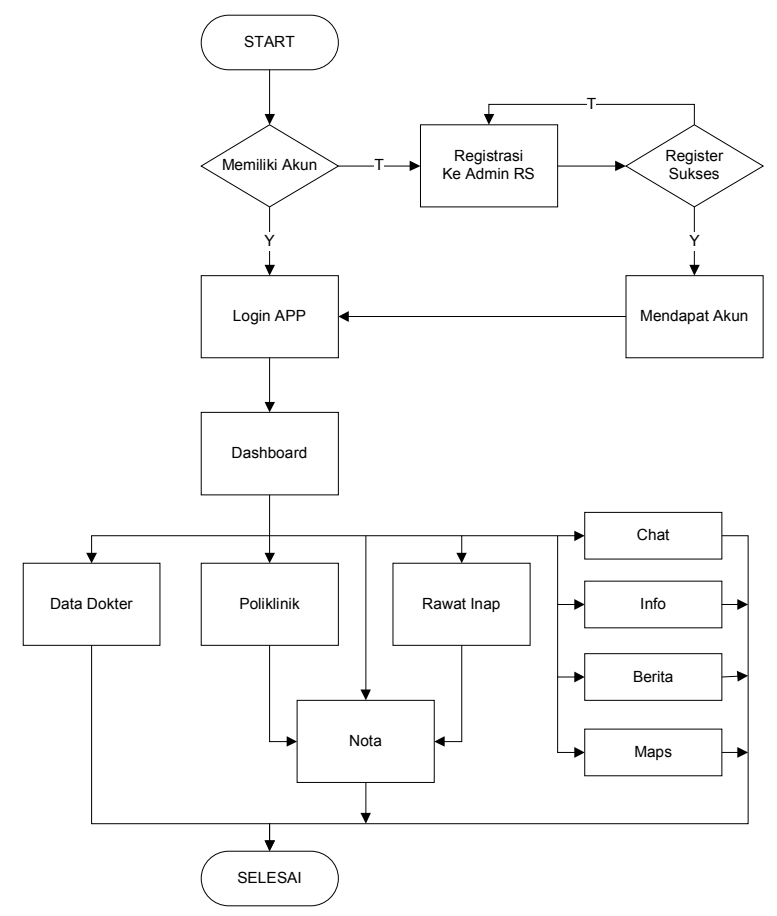

Gambar 7. Diagram Alir Aplikasi

Untuk menguji aplikasi, dimualai dengan melakukan pengunduhan dan pemasangan aplikasi pada berbagai jenis smartphone. Hal ini dilakukan karena pengguna menggunakan berbagai jenis smartphone, maka untuk mngetahui apakah aplikasi dapat digunakan oleh semua pengguna smartphone dilakukan pengujian terhadap beberapa sampel jenis smartphone yang ada di pasaran. Hasil tampilan pada berbagai jenis smartphone ditunjukkan dalam Gambar 8. 


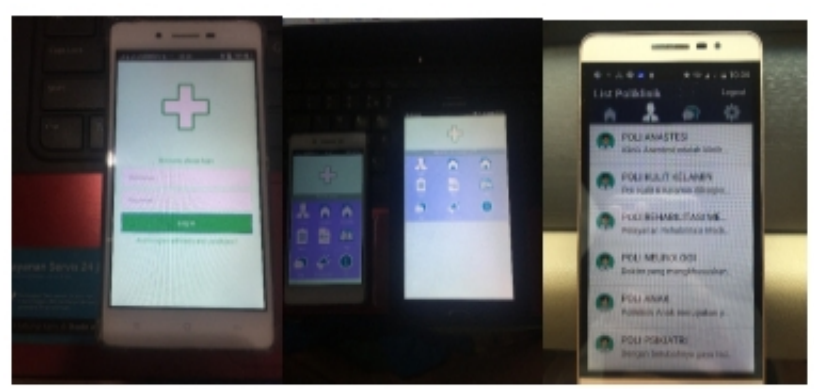

Gambar 8. Tampilan pada Berbagai Smartphone

Spesifikasi Smartphone yang digunakan:

1. Oppo A33W dengan versi OS : V2.1.0i, versi android: 5.1, jenis processor : Quad Core dan RAM : 1,0 GB

2. Samsung SM-T116NU dengan versi OS : V1.2_161011, versi android: 4.4.4, jenis processor : Quad Core dan RAM : 1,0 GB

\section{b) Hasil Kuisioner}

Pengujian kepuasan pelanggan digunakan untuk menguji apakah sudah cukup memenuhi kebutuhan pelanggan dan melihat kekurangan dari aplikasi yang dibuat. Bentuk kuisioner berupa pertanyan berdasarkan aplikasi yang digunakan seperti lengkapnya informasi yang diberikan oleh aplikasi, kelengkapan fitur yang diberikan serta kemudahan dalam melakukan registrasi hingga pemesanan disajikan dalam 5 hasil yaitu sangat setuju, setuju,cukup, sangat tidak setuju dan tidak setuju sebagai pilihan jawaban dan memiliki skor paling tinggi untuk sangat setuju yaitu 5 dan sangat tidak setuju dengan skor 1. Adapaun pertanyaan seputar apakah cukup aplikasi untuk memenuhi kebutuhan dalam proses administrasi di rumah sakit. Kuisioner diberikan kepada 30 orang secara acak dan beberapa hasil ditunjukkan dalam Gambar 9.

\begin{tabular}{|l|c|c|c|c|c|c|c|c|c|c|c|c|}
\hline $\begin{array}{c}\text { Nama } \\
\text { Pelanggan }\end{array}$ & No.1 & No.2 & $\begin{array}{c}\text { No. } \\
\mathbf{3}\end{array}$ & $\begin{array}{c}\text { No. } \\
\mathbf{4}\end{array}$ & $\begin{array}{c}\text { No. } \\
\mathbf{5}\end{array}$ & $\begin{array}{c}\text { No. } \\
\mathbf{6}\end{array}$ & $\begin{array}{c}\text { No. } \\
\mathbf{7}\end{array}$ & $\begin{array}{c}\text { No. } \\
\mathbf{8}\end{array}$ & No.9 & No.10 & Total & $\begin{array}{c}\text { Total } \\
\mathbf{( \% )}\end{array}$ \\
\hline Roni & 4 & 4 & 5 & 4 & 5 & 4 & 3 & 4 & 4 & 4 & 41 & 82 \\
\hline Habibi & 4 & 4 & 5 & 4 & 4 & 5 & 5 & 4 & 5 & 5 & 45 & 90 \\
\hline Riza & 4 & 5 & 4 & 4 & 3 & 4 & 4 & 4 & 4 & 4 & 40 & 80 \\
\hline Jaenal Arifin & 4 & 5 & 4 & 4 & 5 & 5 & 3 & 4 & 4 & 5 & 43 & 86 \\
\hline Azwwar & 4 & 5 & 4 & 3 & 4 & 4 & 4 & 4 & 4 & 5 & 41 & 82 \\
\hline Alfian & 4 & 5 & 4 & 4 & 5 & 4 & 4 & 5 & 3 & 4 & 42 & 84 \\
\hline Riny & 4 & 4 & 4 & 4 & 4 & 4 & 4 & 4 & 4 & 4 & 40 & 80 \\
\hline Yusuf prakasiwi & 4 & 4 & 3 & 4 & 4 & 3 & 4 & 4 & 3 & 4 & 37 & 74 \\
\hline Magdalena W. & 4 & 4 & 4 & 3 & 3 & 4 & 4 & 4 & 3 & 4 & 37 & 74 \\
\hline Fransigka & 4 & 4 & 4 & 4 & 4 & 3 & 4 & 3 & 3 & 4 & 37 & 74 \\
\hline Sesilia & 4 & 4 & 3 & 3 & 4 & 4 & 4 & 4 & 3 & 4 & 37 & 74 \\
\hline Josafat & 4 & 4 & 4 & 3 & 3 & 4 & 4 & 4 & 3 & 3 & 36 & 72 \\
\hline Johana & 4 & 4 & 3 & 3 & 4 & 4 & 4 & 4 & 3 & 3 & 36 & 72 \\
\hline Vivi Aida & 5 & 5 & 4 & 4 & 4 & 5 & 4 & 4 & 4 & 4 & 43 & 86 \\
\hline Fadhli A. & 5 & 5 & 4 & 5 & 4 & 5 & 4 & 5 & 4 & 5 & 46 & 92 \\
\hline Fironike & 4 & 3 & 5 & 4 & 4 & 4 & 4 & 4 & 4 & 4 & 40 & 80 \\
\hline Titania Divi & 4 & 3 & 4 & 5 & 4 & 3 & 4 & 4 & 4 & 4 & 39 & 78 \\
\hline BoomKumiawan & 4 & 4 & 4 & 4 & 4 & 4 & 4 & 4 & 4 & 4 & 40 & 80 \\
\hline
\end{tabular}

Gambar 9. Tampilan Hasil Pehitungan Kuisioner

Hasil prosentase didapatkan berdasarkan skor maksimal untuk masing-masing pelanggan adalah 50, sehingga nilai prosentase kepuasan masing-masing pelanggan dihitung dengan total skor dibagi dengan skor maksimal dikali dengan $100 \%$, dengan parameter kepuasaan adalah sebagai berikut:0-20\% adalah Sangat Tidak Puas, 20-40 \% adalah Tidak Puas, 40-60 \% adalah cukup Puas, 60-80 \% adalah Puas, 80-100 \% adalah Sangat Puas. Hasil perhitungan didapatkan sebesar 80,13\% dimana hasil merupakan penjumlahan prosentase dari 30 pelanggan dibagi 30 dan hasil termasuk kedalam kategori sangat puas. Jadi berdasarkan data diatas maka penggunaan aplikasi terhadap pelanggan di rumah sakit sangat puas dengan fasilitas layanan yang disediakan oleh aplikasi.

\section{PENUTUP}

Berdasarkan hasil perancangan dan pembuatan serta pengujian hasil penelitian maka dapat diambil kesimpulan sebagai berikut:

a. Perancangan menggunakan model view controller (MVC), sehingga pembuatan web serta aplikasi dimulai dengan perancangan model, perancangan view dan terakhir adalah perancangan controller yang merupakan penggabungan model dan view. 
b. Aplikasi dapat melakukan pemesanan dan memberikan informasi sesuai dengan perancangan yaitu daftar dokter, pemesanan dokter spesialis, poliklinik serta pemesanan kamar untuk rawat inap.

c. Hasil kepuasan pelanggan berdasarkan kuisioner yang disebarkan ke 30 orang yang telah mengunduh dan memasang aplikasi pada smartphone mendapatkan tingkat kepuasan sebesar $80,13 \%$.

\section{DAFTAR PUSTAKA}

[1] Rumah Sakit, Wikipedia. Diambil dari sumber: https://id.wikipedia.org/wiki/Rumah_sakit (diakses pada tanggal 16 Februari 2017)

[2] Riske P. Warouw. 2014. Perancangan Aplikasi Voter menggunakan Android untuk pemilihan Ketua Himpunan. Manado : E-journal Teknik Elektro dan Komputer (2014), ISSN: 2301-8402

[3] Joni Maulindar, 2016. Perancangan Aplikasi Tagihan SPP Berbasis Android. Surakarta : Jurnal Sains Tech Politeknik Indonusa Surakarta ISSN : 2355-5009 Vol. 1 Nomor 5 Bulan Juni Tahun 2016

[4]Hakim, Lukmanul. 2013. Bikin Website Super Keren Dengan PHP dan jQuery. Yogyakart:Lokomedia

[5] Thamura, Frans dan Haryanto, Leo dan Muhardin, Endi. Cara Cepat Mengembangkan Solusi Java Enterprise

Dengan Arsitektur MVC (Struts2, Spring, dan Hibernate),Penerbit Bambumas, 2012.

[6] Michael P.I. 2016. Perancangan Sistem Informasi Pertanian Berbasis Web Menggunakan Model View Controller. Salatiga: Jurnal Sistem Informasi, Vol. 8 No. 1, Maret 2013:17 - 28 